\title{
ДИАГНОСТИЧЕСКИЙ КОМПЛЕКС ОЦЕНКИ ФУНКЦИОНАЛЬНОГО СОСТОЯНИЯ ОРГАНИЗМА ЧЕЛОВЕКА, ОСНОВАННОЙ НА ТЕОРИИ УЛЬТРАСТАБИЛЬНОСТИ ЖИВЫХ СИСТЕМ
}

\author{
В. Н. Ильин, Л. И. Черкес \\ Национальный университет физического воспитания и спорта
}

For the first time in a hardware-software complex alongside with the traditional approaches the method based on a concept about human organism behaving like an ultrastable system is applied for an estimation of a functional state of an organism.

Целью работы является создание диагностического комплекса, предназначенного для оперативной автоматизированной оценки функционального состояния организма человека с повышенной прогностической точностью, основанной на теории ультрастабильности живых систем $[1,4]$.

Диагностический комплекс представляет совокупность классических электронных узлов, выполненных на базе операционных усилителей. Интегративная оценка состояния организма производится по данным математического анализа вариаций ритма сердца и дыхания. Датчик сердечного ритма располагается на мочке уха и использует принцип регистрации отраженной световой волны инфракрасного диапазона. В комплексе применен канал измерения частоты дыхательных циклов. Датчик дыхания устанавливается возле носа в месте максимального воздушного потока. Он выполнен на базе терморезистора, который разогревается постоянным током до температуры $60-70^{\circ} \mathrm{C}$. Частота дыхательного цикла $\mathrm{f}_{\mathrm{b}}$ используется для идентификации частотного дыхательного диапазона $\mathrm{f}_{\mathrm{b}} \pm \mathrm{G}(\mathrm{G}-$ среднеквадратичное отклонение) при проведении спектрального анализа ряда кардиоинтервалов. В отличие от ранее применяемого подхода к идентификации частотного спектра дыхательных волн, используемый метод позволяет избегать неопределенности при определении границ диапазонов медленных, дыхательных быстрых, и сверхбыстрых периодических компонент в ритме сердца и повышает достоверность ритмокардиографической оценки функционального состояния организма человека.

В программе реализован метод вариационной пульсометрии, сущность которого состоит в изучении закона распределения кардиоинтервалов как случайных величин в исследуемом ряду их значений. При этом строится гистограмма и определяются различные ее характеристики. Программа также рассчитывает и выводит на экран графики скатерограммы, автокорреляционной и спектральной функций.
Спектральный анализ производится по методу быстрого преобразования Фурье. Определяются все спектральные максимумы в следующих диапазонах; сверхмедленный диапазон (VLF) - от 0 до 0,04 Гц; диапазон медленных волн второго порядка $\left(\mathrm{LF}_{2}\right)-$ от 0,04 до 0,08 Гц; диапазон медленных волн первого порядка $\left(\mathrm{LF}_{1}\right)$ - от 0,08 до 0,15 Гц; диапазон дыхательных (быстрых) волн (BF) - от 0,15 до 0,40 Гц; диапазон сверхбыстрых волн (VHF) - от 0,40 до 1,00 Гц. Дополнительно рассчитываются спектральные индексы (могут принимать четыре значения 0, 1,2 и 3 в зависимости от количества частотных диапазонов в спектре мощности ритмокрадиограммы, в которых присутствуют максимумы) и волновые числа (количество спектральных линий в сверхмедленном диапазоне - $\alpha_{1}$; количество спектральных линий в диапазоне медленных волн второго порядка $\alpha_{2}$; количество спектральных линий в диапазоне медленных волн первого порядка $-\alpha_{1}$; количество спектральных линий во всем диапазоне медленных волн (0-0,15 Гц) - $\alpha=\alpha_{1}+\alpha_{2}+\alpha_{1}$; количество спектральных линий в диапазоне дыхательных (быстрых) волн - $\beta$; количество спектральных линий в диапазоне сверхбыстрых волн - $\gamma$; общее количество спектральных максимумов $-\mathrm{L}=\alpha+\beta+\gamma)$, а также соотношение площадей спектра в медленном, дыхательном и высокочастотном диапазонах.

Для оценки функционального состояния организма в диагностическом комплексе наряду с традиционными представлениями о регуляторных системах организма впервые применен метод, основанный на положении о том, что организм человека представляет собой ультрастабильную систему, которая может находиться только в дискретных состояниях. При внешних воздействиях или спонтанно переход между состояниями происходит скачкообразно по определенным правилам. Эти состояния и правила перехода классифицированы и описаны с помощью спектральных формул и индексов, волновых чисел и комплекса математико-статистических показателей

(c) В. Н. Ильин, Л. И. Черкес 
ритма сердца $[2,3]$. Спектральная формула представляет собой последовательность символов, описывающая характеристики спектральных линий в спектре анализируемого ряда кардиоинтервалов. Живой организм, как ультрастабильная система, может находиться в равновесном состоянии только при определенных соотношениях спектральных компонентов. Стационарными или равновесными состояниями будут те, у которых в спектрах мощности ритмокардиограмм отсутствуют максимумы в диапазон сверхбыстрых быстрых волн (VHF) - от 0,40 до 1,00 Гц. Организм может находиться в таких состояниях длительное время. Квазистационарные состояния возникают за счет активации процессов, связанных с накоплением или расходом энергии. Основным признаком квазистационарного состояния является наличие в спектрах мощности ритмокардиограмм сверхвысокочастотного компонента VHF. Предполагается, что сверхбыстрые компоненты являются отражением деятельности в живом организме быстродействующих ступенчатых механизмов, которые при выводе организма из равновесно-

\section{Литература}

1. Ильин В. Н. Организм человека как ультрастабильная система / В. Н. Ильин, А. Б. Иванов // Известия КБНЦ РАН. -1999. -№ 2. - С. 69-74.

2. Ільїн В. М. Структурно-лінгвістичний підхід до оцінки функціонального стану організму людини / В. М. Ільїн, В. В. Кальниш, Х. А. Курданов // Доп. НАНУ. -2001. - № 6. го состояния (отклонения значений существенных переменных за физиологические нормы) воздействуют на системы регуляции, которые либо удерживают организм в исходном состоянии, либо переводят его по определенным правилам в новое равновесное состояние. Квазистационарные состояния характеризуются наличием спонтанных переходных процессов в организме и время нахождения в них организма ограничено.

Для общей характеристики активности регуляторных систем, классификации функциональных состояний организма и диагностики донозологических и преморбидных состояний применяется интегральный критерий - модифицированный показатель активности регуляторных систем (ПАРС). Абсолютная величина ПАРС представляет собой сумму условных балов оценки суммарного эффекта регуляции, функции автоматизма, устойчивости регуляции ритма сердца, устойчивости регуляции, активности подкорковых нервных центров, вегетативного гомеостаза и типа состояния (стационарного и квазистационарного).

\section{-C. $185-189$.}

3. Ильин В. Н. Применение теории ультрастабильных систем для оценки функционального состояния организма человека / В. Н. Ильин // УСиМ. - 2000. - № 1. - С. 14-19. 4. Конструкция мозга / У. Р. Эшби. - М. : Изд. иностранной литературы, 1962. -398 c. 